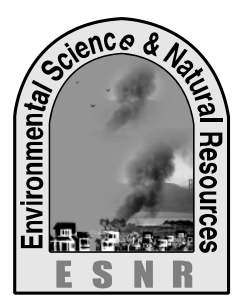

\title{
Feeding Propensity and Cannibalism of Micraspis Discolor (Fab.) to Different Prey Species (Aphis craccivora and Nilaparbata lugens) under Laboratory Condition
}

\author{
M. Z. Islam ${ }^{1 *}$, S. A. Labani' ${ }^{2}$ and A. B. Khan ${ }^{1}$ \\ ${ }^{1}$ Department of Entomology, ${ }^{2}$ Department of Agricultural Finance, \\ Bangaldesh Agricultural University, Mymensingh-2202 \\ * Corresponding author: mohammed_islam26@yahoo.com
}

\begin{abstract}
Feeding propensity and cannibalism of Micraspis discolor (Fab.) to different prey species (bean aphids and brown plant hopper ) was studied in the laboratory of the Department of Entomology, Bangladesh Agricultural University, Mymensingh, during January, 2007 to April, 2007. It was found that the highest pre-oviposition period was to $5.6 \pm 0.54$ days when BPH were used and this period was lowest, $4.6 \pm 0.54$ days using bean aphid. The oviposition period was maximum $40.20 \pm 1.78$ days using bean aphid and minimum $29.00 \pm 2.00$ days were found using BPH. Maximum number of eggs $216.00 \pm 16.58$ was laid when fed on bean aphid. The hatching percent was highest $88.71 \%$ using bean aphid and hatching percent was lowest $85.34 \%$ when fed on BPH. Incubation period varied from $2.40 \pm 0.54$ to $3.80 \pm 0.44$ days using different foods. However, the larvae passed through four larval instars and highest larval period was $10.00 \pm$ 0.70 when BPH were used as food and lowest was 8.40 days feeding on bean aphid. Pupal period was $3.00 \pm 0.00 \& 3.80 \pm 0.44$ days when bean aphid \& BPH were supplied as food. The average longevity of female was $38.60 \pm 3.78$ and $31.40 \pm 2.96$ days and that of male was $32.00 \pm 2.91 \& 26.00 \pm 0.91$ days when feeding on bean aphid and BPH respectively. It was significant at $1 \%$ level. The sex ratio of male and female was found (0.78:1.00) using different foods and these were not significant at $1 \%$ level. By this experiment, It was observed that feeding propensity of Micraspis discolor to different prey species during the total life cycle was as follows: bean aphid > BPH. It was also found that M. discolor had cannibalistic behavior and this was significant at $1 \%$ level.
\end{abstract}

Key words: Cannibalistic behavior, Feeding propensity, Micraspis discolor

\section{Introduction}

Coccinellidae (Coleoptera) is the largest family of the Cerylonid Series CS, including almost 500 genera and 6000 species (Hodek and Honěk, 1996; Seago et al., 2011). The CS series is an artificial group of families within the superfamily Cucujoidea, suborder Polyphaga and it includes the families Cerylonidae, Discolomidae, Alexiidae, Corylophidae, Endomychidae, Lathridiidae and Coccinellidae. The predaceous coceinellids are commonly known as lady bird beetles. They are most useful and important members of arthropod communities in the agro-ecosystem. They are known to be of great economic importance because majority of them are predaceous on aphids, coccids, psyllids hoppers, alurodids and acarids. Three types of feeding regimes are present within the Coccinellidae: predation (zoophagy), plant feeding (phytophagy) and fungus feeding (mycophagy). Most Coccinellidae (90\%) are predators, feeding on the suborder Sternorrhyncha (Iperti, 1999; Giorgi et al., 2009; Seago et al., 2011).Within coccinellids, each taxonomic group is associated with a group of prey: the Sticholotini feed on Coccoidea, the Serangini on Aleyrodidae. The Scyminini and Hyperaspini feed mostly on aphids, the Stethorini feed on mites and spider mites, the Aspiridimerini on aphids. The Chilocorinae and Coccidulinae prey mostly on coccids, except for the tribe Platynaspini. The Coccinellidae are mostly aphidophagous, except for some genus which feed on coccids and the tribe Psylloborini which is mycophagous. The subfamily Epilachninae is phytophagous. Psyllids are consumed preferentially by the tribe Ortaliini (Hodek and Honěk, 1996; Hodek and Honěk, 2009). In addition, some species of coccinellids attack other orders of insects such as Thysanoptera, Lepidoptera, Coleoptera, Hymenoptera and Diptera (Evans, 2009). This generalist behavior is mostly common amongst the aphidophagous species, since those are more prone to suffer starvation in periods of scarcity of their main prey (Dixon, 2000; Sloggett and Majerus, 2000). Species with Coleoptera as their main prey usually comprise large, highly polyphagous individuals (Dixon and Hemptinne, 2001). Cannibalism is also common among some species, especially when food shortage occurs (Hodek and Honěk, 1996; Obrycki and Kring, 1998). The predator status of most ladybirds justifies its importance as regulators of many potential insect pests of agricultural and forest ecosystems (Iperti, 1999). Verania discolor (Fab.), Red colored coccinellid beetle, was recorded as Micraspis discolor Fabricius by Islam and Nasiruddin. The coccinellid beetles belong to the family Coccinellidae of the order Coleoptera and comprise nearly about 5000 species (Imms, 1977). This species is distributed in many countries of Asia, namely, India, Bangladesh, Formosa (Taiwan) and Malaysia (Parker and Sing, 1973; Islam and Nasiruddin, 1978). In Bangladesh it is widely distributed and found throughout the year. They are of great economic importance as majority of them are predaceous both in their larval and adult stages on various important crop pests such as aphids, brown plant hoppers, thrips, coccids, jassids, corn borers, scale insects, mealy bugs, white backed plant hoppers, white flies and other soft bodied insects. Aphids are one of the most widespread groups of pests in agro-ecosystem and may cause crop losses in forest trees, field crops and horticultural crops. Plants may be affected directly or indirectly as a result 
of the presence of aphid population. Bean aphid, Aphis craccivora Koch. attack various plant parts and cause considerable losses in the bean yield. Aphis craccivora Koch. is considered as the most serious pest and may cause $100 \%$ yield loss in different species of country bean(Lablab purpureus),barbate (Vigna sesquipendalis), black gram (Vigna mango), mungbean (Vigna radiate) and cowpea (Vigna nuguiculata) Aphid is one of the most destructive pests whose distribution is worldwide (Begum et al., 1991). Both the nymphs and adults cause damage by sucking sap from flowers, buds, pods and tender shoots of the plants and reduce the vitality of the leguminous crops. The brown plant hopper, Nilaparbata lugens (Stal) (Homoptera: Delphacidae) has become a serious threat in rice production in South, South East and Far East Asia. The brown plant hopper, through direct feeding by sucking cell sap reduces the yield potential. When pest density becomes high, it creates a condition known as 'hopper burn' and the plant dies. Control of aphids, scale insects and brown plant hoppers in Bangladesh is principally carried out by the conventional use of insecticides. An increased knowledge of the biology of M. discolor (Fab.) would increase its utility as a biological control agent. Before releasing it in the agro-ecosystem, detailed study on its life history, feeding habit, predation efficiency, food preference etc. is necessary. The present study on the coccinellid beetle Micraspis discolor was undertaken with the following objectives: i) To study the feeding propensity of M. discolor, ii) To study the predation efficiency of this predator on bean aphid and brown plant hopper. iii) To observe cannibalism of M. discolor.

\section{Materials and Methods}

The experiments were conducted in the Laboratory of the Department of Entomology, Bangladesh Agricultural University, Mymensingh during January to April, 2007. The objective of the present study was to observe feeding propensity and cannibalism of the predator Micraspis discolor (Fab.). The prevailing room temperature and relative humidity during the research period were $23^{\circ} \mathrm{C} \pm 2^{\circ} \mathrm{C}$ and $75 \% \pm 5 \%$, respectively. Details of the materials and methods adopted in the study are discussed under the following subheading.

\section{Collection of different prey species}

Bean aphid (Aphis craccivora) and Brown plant hopper (Nilaparbata lugens) were collected for conducting the experiment. For bean aphid collection, a farmer's field infested with bean aphid was selected which was situated at "Boira" village near Bangladesh Agricultural University, Mymensingh and aphids were collected daily with infested bean leaves, stems, twigs and inflorescence Brown plant hoppers were collected daily from Bangladesh Institute of Nuclear Agriculture (BINA) campus, Mymensingh

\footnotetext{
Mass culture of the Coccinellid predator, Micraspis discolor (Fab.)
}

Adult beetles of M. discolor were collected from Agronomy Field Laboratory, Bangladesh Agricultural University, Mymensingh. These beetles were sexed and paired in petri dishes $(8.5 \mathrm{~cm} \mathrm{X} 1.5 \mathrm{~cm})$. The bottom of the petri dishes were covered with blotting paper. The adults were provided with bean shoots and inflorescence infested with aphid as food. Every day fresh field collected aphids were supplied in the petri dishes as food for the predators. The dishes were examined daily for oviposition. After oviposition, beetle pairs were transferred in different petri dishes and the eggs laid by them were left undisturbed in the petri dishes for hatching. The larvae after hatching of eggs were transferred into peteri dishes $(8.5 \mathrm{~cm} \mathrm{X} 1.5$ $\mathrm{cm})$ and reared till adult emergence. The newly emerged adults were sexed and confined in pairs in petri dishes for mating and laying of eggs. This procedure was continued for several times for obtaining large number of larvae and adult predators for experimental purposes.

\section{Biology study of M. discolor on different food}

Adult beetles were collected from the bean plant and reared on bean aphid. Aphid infested bean twigs were supplied in the petri dishes as food of the predators. A single pair of male and female was kept in seven petridishes $(9 \times 1.5 \mathrm{~cm})$. After mating, the female laid eggs and the beetles were transferred to other petridishes after egg laying and the date of egg laying was recorded. The eggs were observed every day to note the hatching period. The larval and pupal periods were also recorded. The newly hatched grub was isolated in separate petridishes. Five petridishes were maintained (10 grub per petridish). The bottom of the petridishes were covered with blotting paper. Observations were made at 24 hours interval each morning. The grubs were observed daily to examine the larval moult and to record the duration of larval instar. During pupation, predator was kept undisturbed and pupal period was recorded. Mating behaviour of the predator was studied under laboratory condition. To observe the pre-oviposition, oviposition and fecundity the newly emerged adult males and females collected from the mass culture were confined in pairs in the petridishes for mating. The adults were provided with aphid infested shoot or inflorescence or stem of bean plant as food. The date of egg laying was recorded and total number of eggs laid by each female during every 24 hrs. were counted and kept in separate petridish. The viability of the eggs were determined by allowing them to hatch. Hatching period and hatching percentage of eggs were also recorded. Brown plant hopper of known numbers were supplied each morning and five petridishes were maintained. Larval longevity was recorded. Pupal period, hatching period, hatching percentage, fecundity, adult longevity of the predator $M$. discolor were also recorded.

Cannibalism of M. discolor (Fab.) 
The predators, M. discolor were reared in Entomology Laboratory, Bangladesh Agricultural University, Mymensingh. It was observed that cannibalism was mainly due to scarcity of prey species and predator starvation. Usually the eggs and young larvae were more vulnerable as compared to older larvae and adults.From the laboratory stock, in the absence of prey species, eggs of known numbers were supplied to 1 st instar, $2^{\text {nd }}$ instar, 3rd instar, 4th instar and adult each morning and five peteridishes were maintained and the cannibalism behaviour of $\mathrm{M}$. discolor was observed. From the laboratory stock, in the absence of prey species, 1st, 2nd and 3rd instare larvae were supplied as food to 4th instar larvae each morning and three petridishes were maintained and cannibalism behaviour of M. discolor was observed.From the laboratory stock, in the absence of prey species, 1st, 2nd, 3rd and 4th instar larvae were supplied as food to adults each morning and three petridishes were maintained and the cannibalism behaviour of adult M. discolor was observed.

\section{Predation efficiency of larvae}

Just after hatching of egg, young larvae were transferred individually in petridishes $(9 \mathrm{~cm} \times 1.5 \mathrm{~cm})$ from mass culture seven petridishes were maintained for this purpose. The bottoms of the petridishes were covered with blotting paper. The food bean aphids and brown plant hoppers were supplied every morning at the rate of 40 , and 60 and in number for 1st, 2nd, 3rd and final instar larvae respectively. The base of the aphid infested bean and, a brown plant hopper infested rice plant were covered by water soaked cotton pad for protecting it from wilting. The food was changed after 24 hours. The number of aphids and brown plant hoppers consumed within 24 hours and each instar periods were recorded.

\section{Predation efficiency of adult beetle}

For determining the predation efficiency of adult predator, the newly emerged adult beetles were transferred individually in petridishes $(9 \mathrm{~cm} \times 1.5 \mathrm{~cm})$ from laboratory culture for each food and 30 petridishes were maintained. The prey species of known number of bean aphids and brown plant hopper were supplied every day for adult male and female beetle. The number of aphids and brown plant hoppers consumed by adult male and female beetles were recorded every 24 hours and continued till death of the beetles.

\section{Statistical analysis}

Data obtained from the experiments were analyzed in the computer for one factor Completely Randomized Design (CRD) and means were ranked by Duncan's Multiple Range Test (DMRT)

\section{Results and Discussion}

\section{Pre-oviposition period}

It was observed that the females did not lay eggs just after attaining adult stages. The time elapsing between the date of adult emergence and the first egg deposition was considered as pre-oviposition period. The mean pre-oviposition period was found to be $4.6 \pm 0.54$, $5.6 \pm 0.54$ days when fed on bean aphid and brown plant hopper, respectively (Table.1) and these results were not statistically significant.

\section{Oviposition period}

The oviposition period was considered the duration between the period of first and last egg laying by the female. Eggs were laid mainly on the blotting papers, sometimes on the upper and lower leaf surfaces, on stems or on the walls and surfaces of rearing petridish. Eggs were laid vertically in batches. Sometimes the females laid eggs separately in line. Usually they laid 10-25 eggs but sometimes the number per cluster was minimum 4 and maximum 26. Maximum number of eggs was laid during the first few days of oviposition period and then this rate decreased gradually. After completion of oviposition, the female died. The mean oviposition period was found to be $40.20 \pm 1.78$, $29.00 \pm 2.00$ days when fed on bean aphid and brown plant hopper respectively (Table. 2) and these results were statistically significant at $1 \%$ level of DMRT.

\section{Eggs}

A typical egg was small with smooth and shiny surface. The eggs were elongate oval in shape and slightly pointed at both ends. Initially the egg color was yellow orange which gradually changed to pale brown. Blackish eye spots developed just before hatching. The fertilized eggs were more transparent prior to hatching. They were so transparent that the first instar larva could be seen from outside through the egg membrane. The unfertilized egg changed slowly from its original deep orange color to red and after 3 to 4 days they began to shrink due to the fact that no embryo developed inside.

\section{Incubation period}

The incubation period is the duration between the dates of egg laying and hatching. The incubation period was $2.40 \pm 0.54,3.80 \pm 0.44$ days when fed on bean aphid and brown plant hopper respectively (Table.1). These results revealed that the incubation period was highest in brown plant hopper and lowest in bean aphid and it was statistically non-significant.

\section{Larva}

After hatching, the blackish larvae came out from the egg by making irregular hold through the upper end of the egg shell. A single batch of eggs hatched simultaneously and the larvae remained in cluster for almost a day. Larvae were soft bodied, brownish-black, elongate, somewhat flattened and covered with minute spiny structures. There were three ocelli on either side of the head and the mandibles were sickle shaped. Three pairs of legs were long and slender. The larvae were active in preying on aphid. The larvae passed through four larval instars with three moult as confirmed from observations of exuviae in the pertiddish. The average total larval period was $8.40 \pm 0.51,10.00 \pm 0.70$ days when fed on bean aphid and BPH respectively (Table.1). 


\section{Pre-pupal and pupal stage}

The pre-pupal period was the time elapsing between the date when a larva stopped feeding and the data of pupation. At the beginning of the pre-pupal period the larva stopped feeding, became less active and moved slowly. They tried to hide themselves in places like under leaf surfaces or stems or at the bottom of the petridishes for pupation. Duration this period, they curved into $\mathrm{C}$-shaped, remained attached to the surface of the rearing container with posterior end by secreting some deep black fluids. At pupal stage all the larval characters, size and shape were lost. Usually pupa was found reddish in color. No characteristic differences of male and female pupa were noticed except the size. The female pupa was longer than male pupa. The pre-pupal duration was on an average $1.20 \pm 0.44,1.40 \pm 0.54$ and pupal duration was on an average $3.0 \pm 0.0,3.8 \pm 0.44$ days when fed on bean aphid and brown plant hopper respectively (Tab. 1).

\section{Adult longevity}

The adult of M. discolor (Fab.) was red colored. The shape was oval, flat beneath and convex above. Head small and partly concealed by pronotum. The male could be distinguished from the female by their sexual dimorphism. The female was slightly larger than the male. The average longevity of female was $38.60 \pm 3.78$, $31.40 \pm 2.96$ days whereas male lived from $32.00 \pm 2.91$, $26.00 \pm 0.91$ days when bean aphid and brown plant hopper were used as food respectively and these results were statistically significant at $1 \%$ level of DMRT (Table. 1).
From the above discussion it might be concluded that there were considerable variations of the longevity of male and female depending on food supply.

\section{Life cycle}

The life cycle was measured from egg laying to the adult emergence. The length of average life cycle was $15.00 \pm 0.00,19.20 \pm 0.83$ days when bean aphid and brown plant hopper were supplied as food respectively (Table.1). There were no significant differences when bean aphid and brown plant hopper were supplied as food.

\section{Sex ratio}

Sex ratio was determined by counting the number of adults (male and female) developed from the laboratory reared females. The progeny obtained from each female were sexed. The average sex ratio of M.discolor (male; female) was 1.22:1, 0.78:1 when bean aphid and brown plant hopper were supplied as food (Table.1).

\section{Feeding propensity of the adult M. discolor (Fab.)}

An adult predator $M$. discolor (Fab.) consumed on an average of 21,2 bean aphids and BPH respectively after emergence. Their consumption gradually increased up to $17^{\mathrm{th}}$ day and the feeding rate was 62,9 bean aphids and $\mathrm{BPH}$ respectively. Afterwards this rate gradually dropped and became 20, 4 when bean aphids and BPH were used as foods on the $30^{\text {th }}$ day (Fig.1). The average number of prey consumed by adult stage of $M$. discolor (Fab.) was 1051, 190 on bean aphids and BPH respectively.

Table 1. Summary of the responses of M. discolor (Fab.) to different prey species

\begin{tabular}{|c|c|c|c|c|}
\hline Prey species & & Bean aphid & BPH & Level of significant \\
\hline \multicolumn{2}{|c|}{ Pre-oviposition period (days) } & $4.6 \pm 0.54$ & $5.6 \pm 0.54$ & \begin{tabular}{l|l} 
NS \\
\end{tabular} \\
\hline \multicolumn{2}{|c|}{ Oviposition period (days) } & $40.20 \pm 1.78$ & $29.00 \pm 2.00$ & ** \\
\hline Total no. of egg laid & & $216.00 \pm 16.58$ & $174.20 \pm 11.34$ & ** \\
\hline No. of egg hatched & & $191.80 \pm 18.21$ & $148.60 \pm 8.61$ & ** \\
\hline Hatching (\%) & & 88.71 & 85.34 & ** \\
\hline Incubation period & & $2.40 \pm 0.54$ & $3.80 \pm 0.44$ & NS \\
\hline Total larval period & & $8.40 \pm 0.51$ & $10.00 \pm 0.70$ & NS \\
\hline Pre-pupal period & & $1.20 \pm 0.44$ & $1.40 \pm 0.54$ & NS \\
\hline Pupal period & & $3.00 \pm 0.00$ & $3.80 \pm 0.44$ & NS \\
\hline \multicolumn{2}{|c|}{ Total life cycle (egg to adult) } & $15.00 \pm 0.00$ & $19.20 \pm 0.83$ & NS \\
\hline \multirow[t]{2}{*}{ Sex ratio of progeny } & Male & 1.22 & 0.78 & NS \\
\hline & Female & 1 & 1 & \\
\hline \multirow[t]{2}{*}{ Adult longevity (days) } & Male & $32.00 \pm 2.91$ & $26.00 \pm .91$ & ** \\
\hline & Female & $38.60 \pm 3.78$ & $31.40 \pm 2.96$ & \\
\hline
\end{tabular}

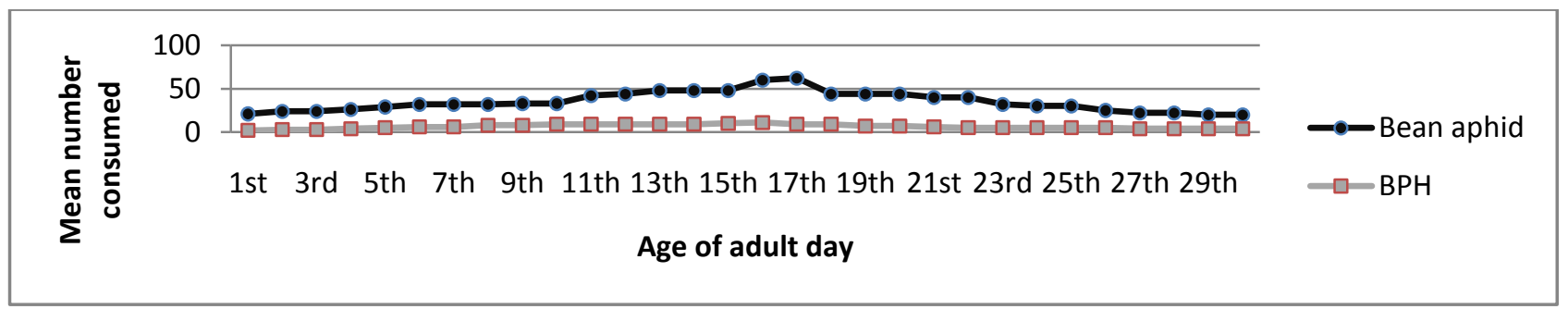

Fig. 1. Age specific bean aphid and BPH consumed by an adult M. discolor (Fab.)

Cannibalism of M. discolor (Fab.)

The rate of egg cannibalism was significantly higher by starved larvae and adults in the absence of prey. $1^{\text {st }}$ instar larvae consumed 2 eggs per day. The $2^{\text {nd }}$ instar larvae consumed 4 eggs per day. The $3^{\text {rd }}$ instar larvae consumed eggs, $1^{\text {st }}$ instar larvae and $2^{\text {nd }}$ instar larvae which were 9,3 and 2 per day respectively in the 
absence of prey. The $4^{\text {th }}$ instar larvae seemed highly voracious and consumed the maximum number of eggs and larvae. The $4^{\text {th }}$ instar larvae consumed eggs, $1^{\text {st }}$ instar, $2^{\text {nd }}$ instar, $3^{\text {rd }}$ instar and $4^{\text {th }}$ instar larvae which were $12,5,4,2$ and 1 per day respectively in the absence of prey. The adult also consumed eggs, $1^{\text {st }}$ instar and $2^{\text {nd }}$ instar larvae which were 15,7 and 6 per day respectively in the absence of prey (Tab.2). The findings of the present study showed that cannibalism occurred in $M$. discolor because of scarcity of the natural food but even in the presence of aphid prey, egg cannibalism was also observed.

Table 2. Cannibalism of $M$. discolor

\begin{tabular}{|l|cccccc|}
\hline Stage & \multicolumn{7}{l|}{ Cannibalism rate of M. discolor } \\
& Egg & 1st instar larvae & 2nd instar larvae & 3rd instar larvae & 4th instar larvae \\
\hline \hline 1st instar larvae & 2 & 0 & 0 & 0 & 0 \\
\hline 2nd instar larvae & 4 & 0 & 0 & 0 & 0 \\
\hline 3rd instar larvae & 9 & 3 & 2 & 0 & 0 \\
\hline 4th instar larvae & 12 & 5 & 4 & 2 & 1 \\
\hline Adult & 15 & 7 & 6 & 0 & 0 \\
\hline Mean $\pm S D$ & $8.4 \pm 5.41$ & $3.0 \pm 3.08$ & $2.4 \pm 2.60$ & $0.40 \pm 0.89$ & $0.20 \pm 0.44$ \\
\hline SE & 2.4 & 1.37 & 1.16 & 0.4 & 0.2 \\
\hline
\end{tabular}

\section{Conclusions}

Based on the findings of the study the following conclusion may be drawn: 1) The suitability of food based on the larval development, adult longevity of $\mathrm{M}$. discolor (Fab.) were as follows: Bean aphid $>\mathrm{BPH}$.

2) The coccinellid beetle, M. discolor (Fab.) had cannibalistic behavior. Usually the eggs and young larvae were more vulnerable as compared to older larvae and adult. The older larvae and adult ate their own stage in the absence of prey which was significant at $1 \%$ level. 3) It has successfully employed in the biological control of some injurious insects such as bean aphids, mustard aphid, scale insects and brown plant hopper.

\section{Acknowledgements}

The authors acknowledge all of the teachers and staffs of the Department of Entomology, Bangladesh Agricultural University, Mymensingh, Bangladesh for their kind cooperation and supports during the study period. The authoress extends her grateful thanks to the Scientist and staffs of the Bangladesh Institute of Nuclear Agriculture (BINA) campus, Mymensingh for supplying necessary information and insects.

\section{References}

Begum, M.; Hussaion, M. and Talukder, F. A. 1991. Relative effectiveness of some granular insecticides against mustard aphid, Lipaphis erysimi (Kalt.). Bangladesh, J. Agril. Sci., 18(1):49-52.
Dixon, A. F. G. 2000. Insect Predator-Prey Dynamics: Ladybird Beetles and Biological Control. New York, USA, Cambridge University Press.

Dixon, A. F. G. and Hemptinne, J. L. 2001. Body size distribution in predatory ladybird beetles reflects that of their prey. Ecology, 82:1847-1856.

Evans, E. W. 2009. Lady beetles as predators of insects other than Hemiptera. Biological Control, 51:255- 267

Giorgi, J. A.; Vandenberg, N. J.; McHugh, J. V.; Forrester, J. A.; Ślipiński, A.; Miller, K. B.; Shapiro, L. R. and Whiting, M. F. 2009. The evolution of food preferences in Coccinellidae. Biological Control, 51:215-231

Hodek, I. and Honěk, A. 2009. Scale insects, mealybugs, whiteflies and psyllids (Hemiptera, Sternorrhyncha) as prey of ladybirds. Biological Control, 51:232-243.

Hodek, I. and Honěk, A. 1996. Ecology of Coccinellidae. p. 464. Dordrecht, The Netherlands, Kluwer Academic Publishers.

Iperti, G. 1999. Biodiversity of predaceous coccinellidae in relation to bioindication and economic importance. Agriculture, Ecosystems and Environment, 74:323-342.

Imms, A. D. 1977. A general text book of Entomology. Edin. E. P. Dutton. NY. 272 p.

Islam, M. A. and Nasiruddin, M. 1978. Life history nand feeding habit of $M$. discolor (F) (Coleoptera: Coccinellidae). Bangladesh J. Biol. Sci., 6 and 7 (1):48-49.

Obrycki, J. J. and Kring, T. J. 1998. Predaceous Coccinellidae in biological control. Annual Review of Entomology, 43:295-321.

Parker, B. L. and Singh, G. 1973. The distribution, feeding habits and fecundity of four coccinellidae. Malaysian Agril. Res., 2(1):6-7.

Seago, A. E.; Giorgi, J. A.; Li, J. and Ślipiński, A. 2011. Phylogeny, classification and evolution of ladybird beetles (Coleoptera: Coccinellidae) based on simultaneous analysis of molecular and morphological data. Molecula Phylogenetics and Evolution, 60:137-151.

Sloggett, J. J. and Majerus, M. E. N. 2000. Habitat preferences and diet in the predatory Coccinellidae (Coleoptera): an evolutionary perspective. Biological Journal of the Linnean Society, 70:63-88. 